EGU2020-9241

https://doi.org/10.5194/egusphere-egu2020-9241

EGU General Assembly 2020

(c) Author(s) 2021. This work is distributed under

the Creative Commons Attribution 4.0 License.

\title{
Integrated geophysical analysis of the April 2017 Moiyabana intra- plate earthquake, Botswana
}

Max Moorkamp ${ }^{1}$, Estella Atekwana ${ }^{2}$, Islam Fadel ${ }^{3}$, Alice-Agnes Gabriel ${ }^{1}$, Folarin Kolawole ${ }^{4}$, Elisha Shemang ${ }^{5}$, Calistus Ramotoroko ${ }^{5}$, Mark van der Meijde ${ }^{3}$, Kevin Mickus ${ }^{6}$, Ame Selepeng ${ }^{5}$, and Loago Molwalefhe ${ }^{5}$

'LMU Munich, Department of Earth and Environmental Sciences, Munich, Germany (max.moorkamp@Imu.de)

${ }^{2}$ University of Delaware

${ }^{3}$ University of Twente

${ }^{4}$ University of Oklahoma

${ }^{5}$ Botswana International University of Science and Technology

${ }^{6}$ Missouri State University

The 3 April 2017 Moiyabana intra-plate earthquake in central Botswana occurred in a region that, until then, had been assumed to be seismically quiet. Its location away from the East African Rift system in a Proterozoic mobile belt between Archean Cratons has raised questions on the triggering mechanism and sparked various studies investigating the crustal and mantle structure in the region, the focal mechanism and the displacement associated with the event. Aeromagnetic and magnetotelluric data indicate movement on a NW striking and NE dipping fault. However, the details of the fault geometry differ when analysing each dataset independently. The geophysical inversion results plus reconstructions of fault movement from InSAR data are all compatible with normal movement and reactivation of a previous thrust fault. An open question though is to which degree fluids are responsible for triggering the event. Here we present first results of reconciling the different available datasets in an integrated analysis. We will show an updated geophysical model of the region around the hypocenter. Such a model can help to shed light on the rupture processes during the earthquake and forms a first step to unravel the genesis of this intra-plate event. 